\title{
Somatostatin in Human Pancreatic and Gastric Juice
}

\author{
A. ARIMURA, K. GROOT, T. TAMINATO, A. ERTAN, K. AKDAMAR, J. RYAN, \\ K. PIENTA* AND A. I. VINIK* \\ Department of Medicine, Tulane University School of Medicine, New Orleans, LA 70112 \\ VA Medical Center, New Orleans, LA 70146 and \\ *Departments of Internal Medicine and Surgery, The University of Michigan, Ann Arbor, MI 48109
}

\begin{abstract}
ARIMURA, A., K. GROOT, T. TAMINATO, A. ERTAN, K. AKDAMAR, J. RYAN, K. PIENTA AND A. I. VINIK. Somatostatin in human pancreatic and gastric juice. PEPTIDES 2: Suppl. 2,271-274, 1981 - Considerable amounts of IRS are secreted after secretin injection in human pancreatic juice collected during endoscopic retrograde cholangiopancreatography. The mean IRS levels in the pancreatic juice of non-diabetic patients were $79 \pm 10(\mathrm{SE}) \mathrm{pg} / \mathrm{ml}$. The IRS levels in NIDDM were considerably higher, the mean value being $1635 \pm 313$ (SE) $\mathrm{pg} / \mathrm{ml}$. The mean IRS level in IDDM were $312 \pm 151$ (SE) $\mathrm{pg} / \mathrm{ml}$. In IDDM, those patients whose blood glucose levels were well controlled by insulin showed low pancreatic juice IRS ranging from non-detectable to $46 \mathrm{pg} / \mathrm{ml}$. On the other hand, those with uncontrolled hyperglycemia showed IRS levels ranging from 452 to $1047 \mathrm{pg} / \mathrm{ml}$. Gel-filtration profiles of IRS in pancreatic juice extracts were not consistent in all cases. Some showed IRS peaks eluting with SS14 and SS28, while others contained IRS species that were eluted in more retarded fractions. The retarded IRS fraction exhibited biological activity indistinguishable from that of SS14 as indexed using a quantitative cytochemical method.
\end{abstract}

Somatostatin (SS14) Somatostatin 28 (SS28) Non-insulin dependent diabetes mellitus (NIDDM) Insulin dependent diabetes mellitus (IDDM) Pancreatic juice Gastric juice

Endoscopic retrograde cholangiopancreatography (ERCP) Pentagastrin Oxyntic cells Secretin

SOMATOSTATIN is found in a variety of organs, and administration of this peptide induces a variety of actions. Furthermore, the stimuli or secretagogues which evoke somatostatin release from these various organs are not necessarily the same. While one substance may stimulate somatostatin release from one organ, it may also inhibit secretion from another [3]. These findings suggest that somatostatin may be a local hormone regulated by specific stimuli more or less unique to the respective organ. Regardless of whether or not somatostatin is secreted in a paracrine or endocrine manner via local portal circulation, its action appears to be confined to the vicinity of its site of secretion. Somatostatin is also released into the gastric and intestinal lumen in animals [11]. However, there are few studies of the intraluminal secretion of somatostatin in humans. Recently we demonstrated the presence of a high concentration of immunoreactive somatostatin (IRS) in human pancreatic juice [6]. The concentration was considerably higher in pancreatic juice from patients with non-insulin dependent diabetes mellitus (NIDDM) than non-diabetic patients. In one patient with insulin dependent diabetes mellitus (IDDM), the concentration was lower than that of all of the non-diabetic patients. However, whether a low concentration of IRS is a general feature of IDDM is unclear. The present study was conducted to further examine this problem and to obtain information on the chemical characteristics of IRS in pancreatic juice. This paper also reports a preliminary study on somatostatin in human gastric juice.

\section{METHOD}

Fifteen subjects without pancreatic and biliary diseases, and 5 NIDDM patients and 7 IDDM patients were studied. Pancreatic juice was collected during endoscopic retrograde cholangiopancreatography (ERCP) by the method described by Kawanishi et al. [8]. All subjects were sedated with IV meperidine $(50-100 \mathrm{mg})$ and/or diazepan $(5-10 \mathrm{mg})$. To facilitate cannulation, the patients also received IV atropine $(0.4-0.6 \mathrm{mg}$ ) and/or glucagon (1-3 U) (Eli Lilly and Co.) to obtain adequate relaxation of the duodenum and the sphincter of Oddi. The cannula was introduced at least $5 \mathrm{~mm}$ into the pancreatic duct and secured. When a successful cannulation was achieved, secretin (1 $\mathrm{U} / \mathrm{kg})$ was given as a single IV bolus injection. Boots secretin (Warren Teed Lab., USA) was given to 15 patients, and Karolinska secretin (GHRU, Karolinska Institute) were given to 12 patients. Pancreatic juice was collected under gentle negative pressure with a $10 \mathrm{ml}$ syringe. Two to three $\mathrm{ml}$ of pancreatic juice initially collected were discarded and the secretion collected over the subsequent $15 \mathrm{~min}$ was utilized for somatostatin assay. After collecting pancreatic juice, a contrast material (Renografin) was injected. Pancreatograms were obtained in all 27 patients. Specimens were immediately mixed with aprotinin, $500 \mathrm{KIU} / \mathrm{ml}$, (Trasylol, FBA Pharmaceuticals, Germany) in ice-chilled tubes and stored at $-60^{\circ} \mathrm{C}$ until assayed. To one $\mathrm{ml}$ of pancreatic juice was added $0.1 \mathrm{ml}$ concentrated acetic acid/concentrated formic acid (1/1) and then $4 \mathrm{ml}$ acetone. The sam- 
ples were then vortexed and centrifuged at $2000 \mathrm{rpm}$ for 15 min at $4^{\circ} \mathrm{C}$. The supernatant was decanted into a tube coated with $0.1 \%$ gelatin and $1 \mathrm{ml}$ water was added to dilute the acetone, followed by $6 \mathrm{ml}$ of organic solvent (ethyl acetate/ether=3/1). Samples were then mixed, and centrifuged at $2000 \mathrm{rpm}$ for $5 \mathrm{~min}$. After the upper (organic) layer was aspirated off the aqueous phase was dried at $40-45^{\circ} \mathrm{C}$ under $\mathrm{N}_{2}$ gas. The extraction procedure used eliminates nearly all proteins including enzymes, lipids, and pigments, and therefore minimizes possible interferences in RIA with these substances. The dried residue was dissolved in RIA diluent and aliquots were assayed for somatostatin.

Some extracts of the pancreatic juice which contained a high concentration of or extracts of pooled pancreatic juice from non-diabetic patients IRS were chromatographed on a Sephadex G-25 (fine) column using $1 \mathrm{M}$ acetic acid containing $0.05-0.1 \%$ gelatin as eluant. All fractions were lyophilized, dissolved in RIA diluent or water, and assayed for somatostatin by RIA. The bioactivity of some of the fractions was also determined by measuring their ability to stimulate carbonic anhydrase activity in guinea pig stomach oxyntic cells using quantitative cytochemistry. A linear log dose-response was obtained between $2.9 \times 10^{-14} \mathrm{M}$ to $2.9 \times 10^{-11} \mathrm{M}$ in this method [10].

RIA was performed as described elsewhere using a rabbit anti-somatostatin serum $R 101$ [1]. In some assays, antiserum R207 was also used. The recognition sites of $R 101$ are directed towards positions 5 to 13 of the somatostatin 14 (SS14) molecule, including the rind portion, whereas R207 is directed towards the $\mathrm{N}$-terminal amino acids. Both elongation and deletion of the $\mathrm{N}$-terminal amino acids results in a loss of binding activity with antiserum R207. Antiserum $\mathrm{R} 101$ and $\mathrm{R} 207$ were used at final dilutions of 1:21,000 and $1: 7,000$ respectively. ${ }^{125} \mathrm{I}-\mathrm{N}$-Tyr-SS and ${ }^{125} \mathrm{I}-\mathrm{Tyr}^{11}$-SS were used as the radioligands for RIA with antiserum R101 and R207, respectively.

Gastric juice was collected from 6 non-diabetic and one NIDDM patient after overnight fasting. The gastric tube was inserted so that its end was located at the proximal portion of the antrum. After the residual content was aspirated, gastric juice was collected by continuous gentle aspiration for 4 consecutive $15 \mathrm{~min}$ periods. Then, pentagastrin $(0.6 \mu \mathrm{g} / \mathrm{mg})$ or secretin (2 U/kg) was administered IV as a bolus injection. Gastric juice was collected for 4 additional 15 min periods. Specimens were immediately placed in ice-chilled tubes containing Pepstatin A $(100 \mu \mathrm{g} / \mathrm{ml})$ an inhibitor of the enzyme pepsin, which may degrade somatostatin at low $\mathbf{p H}$. After mixing, gastric juice was then neutralized with $0.1 \mathrm{~N}$ $\mathrm{NaOH}$ and placed in boiling water for $10 \mathrm{~min}$. The specimens were then cooled and stored at $-60^{\circ} \mathrm{C}$ until assayed. Boiled gastric juice was determined for somatostatin by RIA without extraction. Bound and free hormone were separated by a double antibody method. The mean recoveries of $100 \mathrm{pg}$ and $500 \mathrm{pg} / \mathrm{ml}$ of added somatostatin were 78 and $96 \%$, respectively.

\section{RESULTS AND DISCUSSION}

In non-diabetic patients, pancreatic juice immunoreactive somatostatin (IRS), in terms of SS14, ranged from 43 to 201 $\mathrm{pg} / \mathrm{ml}$, averaging $79 \pm 10(\mathrm{SE}) \mathrm{pg} / \mathrm{ml}$. These values were considerably greater than the IRS values in the peripheral plasma processed by a similar method. These plasma IRS levels were less than $20 \mathrm{pg} / \mathrm{ml}$ during fasting [1]. There were no significant differences in pancreatic juice IRS levels
TABLE 1

IRS (PG/ML) IN HUMAN PANCREATIC JUICE EXTRACTS FROM NON-DIABETICS, NIDDM AND IDDM

\begin{tabular}{lccc}
\hline & Non-Diabetics (15) & NIDDM (5) & IDDM (7) \\
\hline Mean & 79 & 1635 & 312 \\
\pm SDM & 38 & 700 & 400 \\
\pm SEM & 10 & 313 & 151 \\
Range & $43-201$ & $843-2287$ & $0-1047$ \\
\hline
\end{tabular}

associated with age or sex of the patients. Glucagon or atropine, which were administered before ERCP, did not seem to affect IRS levels. Thus, IRS levels in non-diabetic patients were found within a fairly narrow range after administration of various doses of these drugs, or without receiving either of them (Table 1).

Surprisingly, IRS levels in NIDDM were 10-30 times greater than those in non-diabetic patients. On the other hand, IRS levels in IDDM varied considerably (Table 1). Four out of seven IDDM showed low IRS values ranging from non-detectable to $46 \mathrm{pg} / \mathrm{ml}$, whereas the remaining 3 patients showed high IRS levels ranging from 452 to 1047 $\mathrm{pg} / \mathrm{ml}$. It is interesting that IDDM patients with low IRS were well controlled by insulin, whereas those with high IRS levels were poorly or only moderately controlled. On the other hand, all of the patients with NIDDM were well controlled by an appropriate diet or small doses of insulin. Therefore, it is unlikely that the levels of IRS in the pancreatic juice were directly related to the levels of blood glucose. However, a fundamental difference in exocrine IRS secretion appears to be present between NIDDM and IDDM. Although exocrine IRS secretion clearly increases in all NIDDM and uncontrolled IDDM, and decreases in controlled IDDM, it is still not certain if this change parallels the endocrine secretion of pancreatic somatostatin.

It was necessary to administer secretin or glucagon to obtain sufficient amounts of pancreatic juice. Since both secretin and glucagon are known to stimulate endocrine IRS release, the IRS values obtained in this study may not represent the basal exocrine secretion of somatostatin. It is possible that the differences in the IRS levels between nondiabetics and NIDDM, and those between non-diabetics and controlled IDDM, are due to hyper-responsivity to the secretagogue in NIDDM and hyposensitivity in the controlled IDDM. Although the glucagon and Boots secretin preparations are slightly contaminated with somatostatin $(4 \mathrm{pg} / \mathrm{U}$ and $7 \mathrm{pg} / 100 \mathrm{U}$, respectively), it is unlikely that the IRS in the pancreatic juice originates from this contamination. This suggestion is strengthened by the observation that similar IRS levels were obtained after injection of Karolinska secretin, which is devoid of somatostatin. However, our results stand in contrast to those of Conlon et al. [5] who found that dog pancreatic juice was devoid of IRS during secretin stimulation.

In $\mathrm{ob} / \mathrm{ob}$ or $\mathrm{db} / \mathrm{db}$ diabetic mice, which are considered to resemble NIDDM in humans, pancreatic and gastric somatostatin contents are lower than those of non-diabetic control animals [4]. On the other hand, in streptozotocininduced diabetic rats, which may resemble IDDM, the con- 


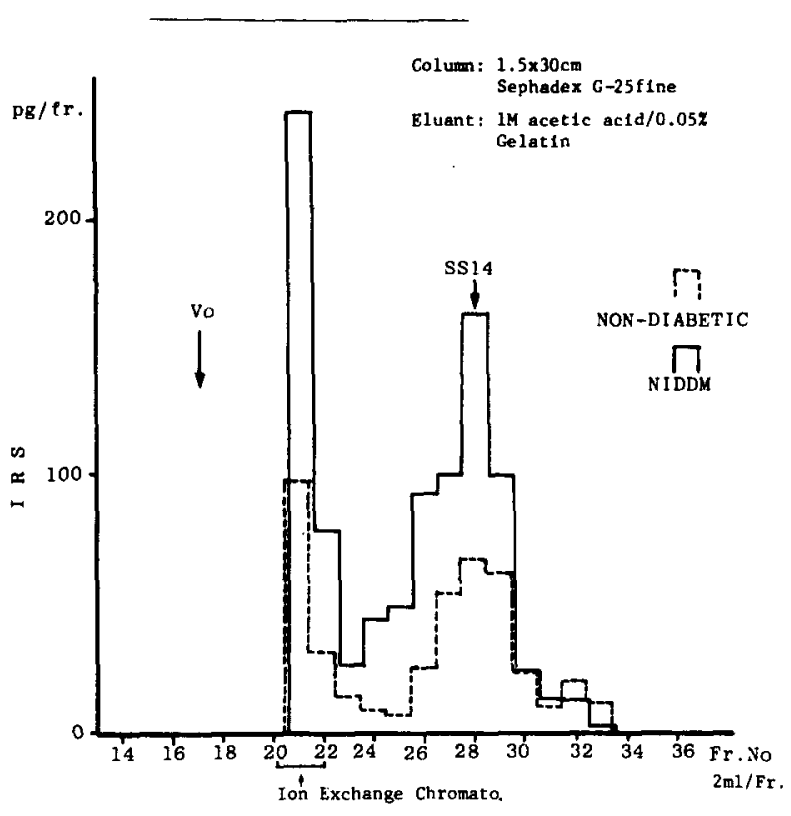

FIG. 1. Gel filtration profile of immunoreactive somatostatin (IRS) in human pancreatic juice extracts, obtained from non-diabetic (pooled) and one NIDDM patients. Immunoreactive somatostatin (IRS) from the fractions were determined by RIA using Anti SS \#101. Rf (latter peak) $=0.48$, $\mathrm{Rf}$ (earlier peak) $=0.61$. The column parameters are shown in the figure.

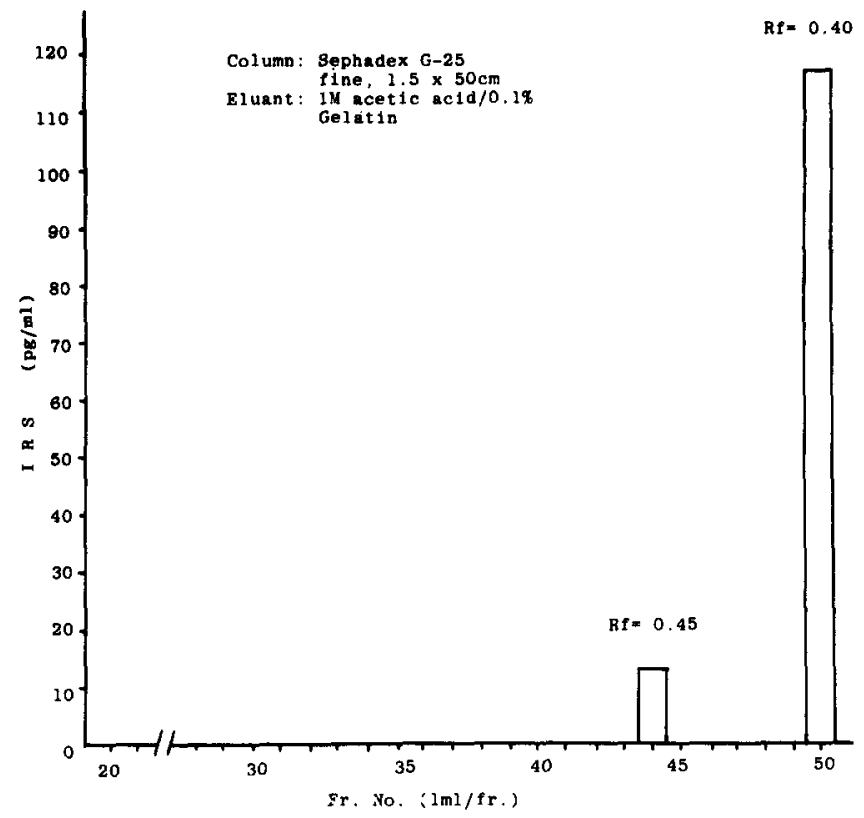

FIG. 3. Gel filtration of human pancreatic juice extract from an NIDDM patient other than the one in Fig. 1. IRS from the fractions were determined by RIA using Anti SS \#101. Rf (latter peak) =0.40, $\mathrm{Rf}$ (earlier peak) $=0.45$. The column parameters are shown in the figure.

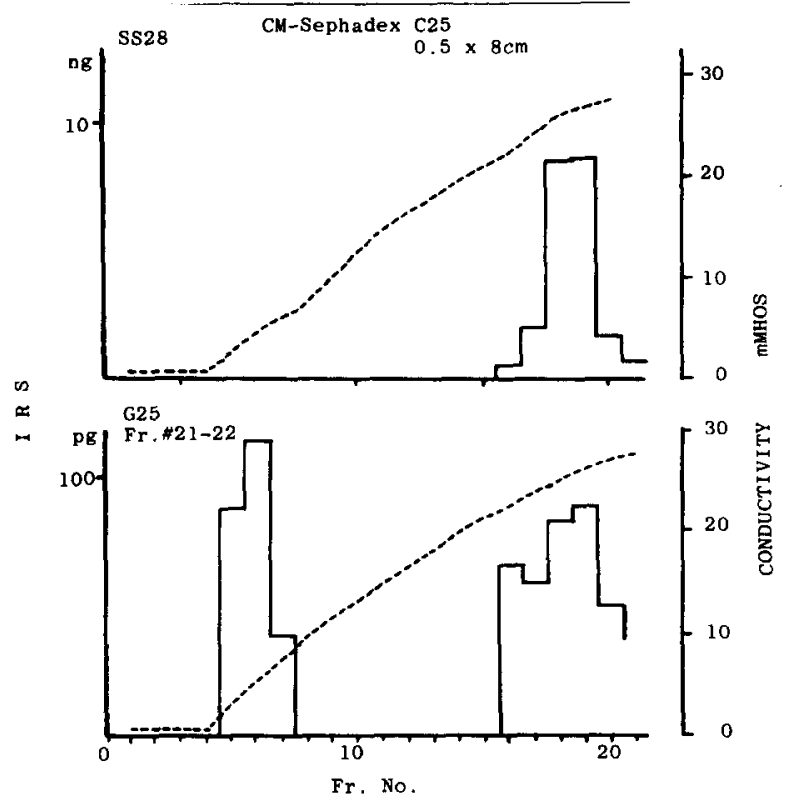

FIG. 2. Ion exchange chromatography of somatostatin 28 , SS 28 (upper panel), and big immunoreactive somatostatin, big IRS, (lower panel) in human pancreatic juice extract. IRS from the fractions were determined by RIA using Anti SS \# 101. As shown in the lower panel, fractions 21-22 from Fig. 1 were subjected to ion exchange chromatography on CM-Sephadex C-25.

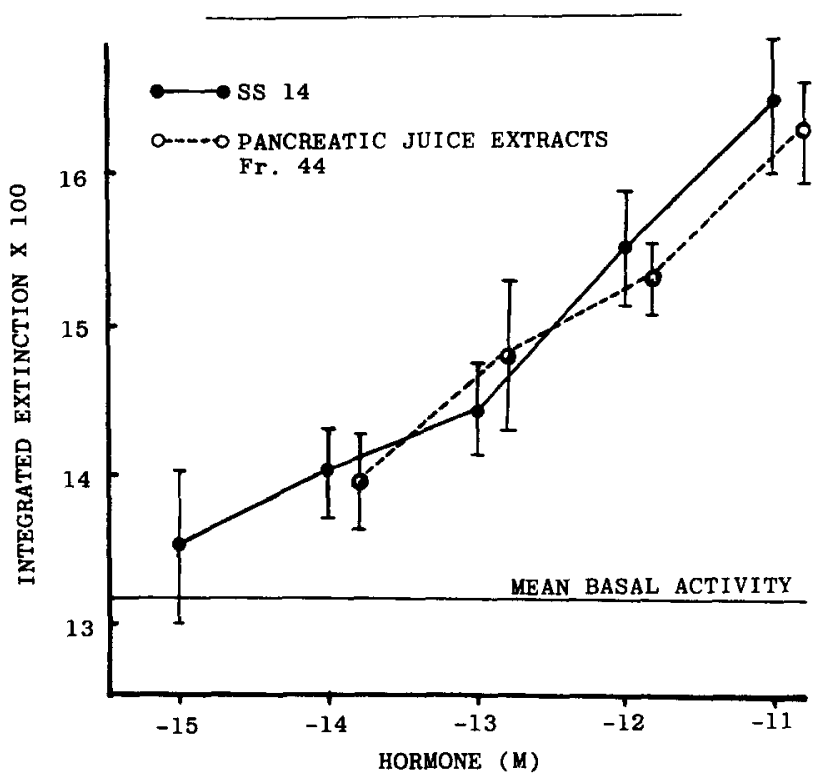

FIG. 4. Somatostatin activity measured by a quantitative cytochemical method. Fr. 44 from the pancreatic juice extract, represented in Fig. 3, was examined for biological activity using quantitative cytochemistry in the guinea pig stomach oxyntic cell system. Dose response curves of SS14 and fraction 44 are shown. 
tent of somatostatin in the pancreas and the stomach is elevated. Plasma IRS levels are also elevated in streptozotocininduced diabetic rats [2]. Therefore, we expected that if any differences in pancreatic juice IRS were found, they would rise in IDDM and decrease in NIDDM. This, however, was not the case.

The route through which pancreatic somatostatin is secreted into the pancreatic juice remains to be clarified. Fujita et al. [7] reported an insulo-acinar system which could carry islet somatostatin. Endocrine cells found throughout the non-islet portion could also be a source of IRS in exocrine pancreatic secretion [9].

Gel-filtration of pancreatic juice extracts from nondiabetics (pooled) and one NIDDM patient yielded similar IRS profiles (Fig. 1). In both case two IRS peaks were found. The latter peak $(R f=0.48)$ was considerably larger than the earlier peak $(R f=0.61$ ). The latter peak also coeluted with SS14 whereas the earlier peak coeluted with SS28. Both this early peak and the retarded peak were detected by antiserum R101 which requires integrated ring structure necessary for biological activity. When the earlier peak was subjected to ion exchange on CM-Sephadex C-25, two IRS peaks were eluted, one eluting with SS28 and the other eluting in earlier fractions (Fig. 2). Whether the IRS species eluting with SS28 indeed represents SS28 requires further chemical identification.

Gel-filtration of pancreatic juice extract from an NIDDM patient also showed 2 IRS peaks, but both peaks were eluted in fractions more retarded than those containing SS14 (Fig. 3 ). The earlier fraction was examined for biological activity using quantitative cytochemistry in the guinea pig stomach oxynic cell system by Shapiro et al. [10]. The dose response curve of this fraction was superimposable on that obtained with SS14 in the range between $10^{-11}$ and $10^{-14} \mathrm{M}$ of the extract in terms of SS14 in RIA (Fig. 4). Although we have not completed examining all IRS peaks on gel-filtration, it is likely that the IRS in pancreatic juice detected by antiserum $\mathrm{R} 101$ is biologically active.

In contrast to pancreatic juice, the IRS levels in most gastric juice specimens were undetectable or very low before and after stimulation with pentagastrin or secretin, except in one case of NIDDM. The possibility that the low values were due to degradation of somatostatin by enzymes during collection cannot be excluded. However, in one patient with NIDDM, gastric juice IRS levels rose considerably during the second and third collections after pentagastrin stimulation $(21.3 \mathrm{ng} / \mathrm{ml}$ and $30.5 \mathrm{ng} / \mathrm{ml}$, respectively). Whether this is a general response in NIDDM awaits further investigation.

\section{REFERENCES}

1. Arimura, A. Radioimmunoassay for somatostatin in tissue and blood. In: Comprehensive Endocrinology, edited by G. B. J. Glass. New York: Raven Press, 1980, pp. 841-854.

2. Arimura, A. and W. L. Case. Somatostatin reserve in the gut and pancreatic D-cells in normal and streptozotocin-induced diabetic rats. Biomed. Res. 1: Suppl. 1, 149-153, 1980.

3. Arimura, A. Progress in neuroendocrinology, somatostatin: regulation of secretion. Neuroendocrinology, in press, 1981.

4. Baeten, S. D., Y. Stefan, M. Ravazzola, F. Mallaisse-Lagae, D. L. Coleman and L. Orci. Alteration of islet cell population in spontaneously diabetic mice. Diabetes 27: 1-7, 1978.

5. Conlon, J. M., D. Rouiller, G. Boden and R. H. Unger. Characterization of immunoreactive components of insulin, and somatostatin in canine pancreatic juice. FEBS Lett. 105: 23-26, 1977.

6. Ertan, A., T. Taminato, K. Akdamar, J. Ryan, N. M. Agrawal, A. V. Schally and A. Arimura. Immunoreactive somatostatin in human pancreatic secretion. J. clin. Endocr. Metab. 52: 589$591,1981$.
7. Fujita, T., Y. Yanatori and T. Murakami. Insulo-acinar axis, its vascular basis and its functional and morphological changes caused by CCK-PZ and caerulein. In: Endocrine Gut and Pancreas, edited by T. Fujita. Amsterdam: Elsevier Scientific Publishing Co., 1975, pp. 347-358.

8. Kawanishi, H., J. E. Sell and H. M. Pollard. Combined endoscopic fluid collection and retrograde pancreatography in the diagnosis of pancreatic cancer and chronic pancreatitis. Gastrointest. Endosc. 22: 82-85, 1975.

9. Melmed, R. N. Intermediate cells of the pancreas: An appraisal, Gastroenterology 76: 196-201, 1979.

10. Shapiro, B., K. Pienta, A. Heldsinger and A. T. Vinik. Somatostatin is an agonist and non competitive antagonist of gastrin in oxyntic cell function. Endocrinology 109: 1117-1121, 1981.

11. Uvans-Wallensten, K., J. M. Lundberg, S. Efendic. Dopaminergic control of antrum gastrin and somatostatin release. Acta physiol. scand. 103: 343-345, 1978. 